\title{
No Future: The Study of Culture in the Twenty-first Century
}

\section{Preface}

This lecture was written for the occasion of a celebration in July 2016, marking the 10th and 15th anniversaries respectively of the University of Giessen's GCSC and GGK. It was, in retrospect, a more innocent time, when my colleagues from outside the US were asking curiously if Donald Trump could really be elected president of the United States, which I assured them was extremely unlikely to happen. If I were asked to write a similar lecture today my premediation of "no future" for the study of culture in the twenty-first century would seem even more on point than it might have then.

My own involvement with these two graduate programs began in March 2010 when I delivered the opening plenary address at "The Arts of Mediation," a summer conference at the Catholic University of Lisbon, organized as part of the PhDnet, of which the University of Giessen is a founding member. At that time I was in the process of finalizing the details of an offer to direct the Center for 21st Century Studies (C21) at the University of Wisconsin-Milwaukee. Initial discussions with Ansgar Nünning about the GCSC persuaded us both that it would be good to work together. Within a year, we had written and signed off on a memorandum of agreement between the two centers that we would collaborate in the future. Beginning with master classes, lectures, and meetings in Giessen, we developed plans for collaboration. Working primarily with Martin Zierold and Beatrice Michaelis, I helped to organize the May 2013 GCSC conference on "The Re/turn of the Nonhuman in the Study of Culture," which was co-sponsored by C21. Our most substantial collaboration was a \$1.5 million Andrew Mellon Foundation-funded program in Interdisciplinary Graduate Humanities Education Research and Training (IGHERT), a program that also involved humanities centers at University of California-Santa Cruz and Australian National University, Canberra.

In 2011 while working out the details of our letters of intent to collaborate, I sent Ansgar Nünning a copy of the inaugural lecture I had delivered at University of Wisconsin-Milwaukee in October 2010, entitled "The Future of 21st Century Studies." I like to think that the Anniversary Symposium on "Futures of the Study of Culture" was at least partly indebted to that inaugural lecture, which argued that the future of the study of culture lay in the interdisciplinary academic field 
called twenty-first-century studies. I know that my argument in this lecture shares some points of contact with that earlier piece, which addressed the future of twenty-first-century studies, particularly as it manifests itself in the arts, humanities, and social sciences, the traditional areas of focus among centers like C21 and GCSC.

\section{Framework for the Study of Culture in the Twenty-first Century}

What do I mean by claiming that there is no future to the study of culture in the twenty-first century? My thesis is that we are (or should be) nearing the end of the study of culture, and that if we as academics continue to study it as we have since at least Kant and Herder we will run the risk of irrelevance, or worse. In this chapter I maintain that there is no future for the study of culture if it does not include the study of key concerns of the twenty-first century, including especially those ecological, geopolitical, and economic issues that threaten the existence of culture as we know it, but which have historically been defined in opposition to cultural issues.

I intend by the phrase "no future" to make two allusions. The first is to the powerful refrain to the Sex Pistols' 1977 anthem, “God Save the Queen,” whose sympathy for the working class and resentment of the monarchy have recently refigured themselves very differently in the wake of the 2016 Brexit referendum (Sex Pistols 1977). In alluding to the Sex Pistols song I mean to call attention to the way in which the study of culture in the academy is currently threatened by the politics of austerity and securitization that have emerged in the EU and the US as a preemptive response to the threat of global terrorism.

The second allusion in my title is to Lee Edelman's 2004 book, No Future: Queer Theory and the Death Drive (Edelman 2004). In remediating Edelman's title, I want both to borrow from and to expand his argument. I borrow from his project the concern to destabilize or "queer" normative notions of time, particularly of reproductive futurity. Both the nation state and the academy operate according to a temporal framework in which their institutional form is reproduced indefinitely into the future. Insofar as the contributors to this volume have been asked to imagine the institutional reproduction of an academy in which the study of culture will still have a place, the editors of this volume imagine the reproduction of an academic future that looks very much like the present. For Edelman a queer ethics negates the conservative political project of reproductive futurism. Queerness, Edelman argues, "comes to figure the bar to every realization of futurity, the resistance, internal to the social, to every social structure or form" (Edelman 
2004, 4). I want, then, in this chapter, to try to "queer" the future of the study of culture. Although I follow Edelman in thinking about how we might queer the future of the study of culture in the twenty-first century, I want to move beyond the concerns with the human and the literary that Edelman's book foregrounds, and that the notion of culture customarily entails.

My thinking about the future of the study of culture in the twenty-first century was first formalized in September 2010 when I delivered a lecture to mark the commencement of my directorship of the Center for 21st Century Studies at the University of Wisconsin-Milwaukee, a position I held until August 2015. In that 2010 lecture I described the state of twenty-first-century studies at the start of the century's second decade to articulate what I saw as some of the key issues that should occupy scholars as they invented this emergent interdisciplinary field. So what did I mean by twenty-first century? My initial response was to define twentyfirst century in the following three ways. These definitions focus mainly on the humanities, arts, and culture. But as I will suggest later in this chapter, the future of twenty-first-century studies cannot end with these disciplines. Nonetheless, it is here that twenty-first-century studies must begin.

First, twenty-first-century studies can be defined as the interdisciplinary studies of the humanities as they are currently being practiced in the twenty-first century, i.e., contemporary, cutting-edge study of the arts, humanities, and culture in all fields, and at all historical periods. In other words, twenty-first-century studies names the most up-to-date, contemporary manifestation of work in the academy. To help explain what this means I would borrow the words of Walter Benjamin who described the vocation of an educated journal as being "to proclaim the spirit of its age. Relevance to the present is more important even than unity or clarity" (Benjamin 1996, 292). In proclaiming the spirit of its age, twenty-first-century studies should not be about establishing a coherent program or intellectual project but rather about an active engagement with and representation of contemporary thought and criticism. This commitment to the contemporary does not mean that twenty-first-century studies is only concerned with the present moment. Indeed, as Benjamin would be the first to argue, it is often the past that can most effectively illuminate the present moment in its specificity. ${ }^{1}$

1 An interesting recent example of how the study of the humanities in any historical period can engage with issues of contemporary concern can be found in the decision of the Medieval Studies Association NOT to move its 2011 meeting from Arizona in protest of its current immigration laws but to use the conference to highlight the way in which the concerns at stake in Arizona's recent legislative attempt to criminalize immigrants could also be seen at work in different ways in the medieval period. As detailed in the online Inside Higher Education: "So rather than move the meeting, the academy plans 'to ensure that the program of the meeting reflects and relates to 
In addition to being defined as the current state of interdisciplinary research in the arts, humanities, and social sciences, twenty-first-century studies can also be defined as the study of the key issues of the twenty-first century, which means in the first instance studies of the present and very recent past, of issues of pressing concern for the twenty-first century. But the study of the twenty-first century also means, now, that the study of the twentieth century has become historical in its incarnation as the century prior to ours as well as in its role as the final century of the second millennium. In this sense, then, the twentieth century is the new nineteenth century. Already in the first decades of the current century scholars have set out many of the key themes for the decades to come, almost all of which have emerged from the concerns of the late twentieth century but take particular forms when placed in relation to our twenty-first century future. Thus, issues like climate change, terrorism, finance, mobility, migration, security, sexual equality, water, food, health care, networked media, biotechnology, geo-engineering, and other concerns provide an ample field of research for twenty-first-century studies. Add to this the growing interest in future studies and it is easy to see that twentyfirst-century studies is clearly a growth field.

Third, twenty-first-century studies can be defined as a synthesis of the first two definitions. That is, as I have found to be the case in my own work, particularly on digital mediation, by studying what is distinctive about the issues of the present or near future, we are also able to rethink or reconceptualize our study of the past, which in turn allows us to understand our present situation in a different light. This scholarly feedback system operates in almost every field of the humanities and social sciences, as, for example, contemporary concerns with questions of gender and sexuality prompted scholars to investigate earlier historical formations of queer, straight, and other sexualities, which in turn provided new insights on our own gendered and sexual formations. The same thing can be seen in the way in which, say, an enterprise like critical race studies has both provided new perspectives on and been strengthened by historical study of racial science. Similarly, interest in new forms of digital media has helped both to accentuate study of earlier media formations like photography, print, or linear perspective and to remind us that what was most new about our new media was the way in which they remediated prior media formations. This is one of the most interesting consequences of studying the concerns of the twenty-first century, the way in which they help to transform our received understandings of the history

similar issues at stake in medieval society, including such topics as race, ethnicity, immigration, tolerance, treatment of minority groups, protest against governmental policies judged unjust, and standards of judicial and legislative morality." [http://www.insidehighered.com/layout/ set/print/news/2010/08/04/medieval]. 
of the humanities, arts, and social sciences, and how these new historical understandings help transform our current moment.

Indeed, one thing that should be evident from the definition of twenty-first-century studies I offered in 2010 is that for this emerging interdisciplinary field to engage the key issues of the day, it cannot focus on the humanities, arts, and social sciences alone. If twenty-first-century studies is to engage the crucial issues of the day, it is going to have to engage all of those other academic disciplines that have traditionally been seen as distinct from the concerns of the humanities. Because the dividing lines between science, technology, art, society, and culture are becoming increasingly blurred, it is essential for the humanities to collaborate with and reach out to scientific, technological, political, and economic disciplines. And conversely, if scientific and technological disciplines are going to answer the complex transdisciplinary questions that mark the first decades of the twenty-first century, they are going to have to engage and enroll the humanities, arts, and humanistic social sciences in doing so. Although in the twentieth century the study of culture has been distinguished from the natural, physical, and social sciences, from computation, engineering, or business, much as the human has been opposed to the nonhuman, in the twenty-first century these clear-cut divisions can no longer obtain. Borders are becoming increasingly difficult to draw, as questions of genetic engineering, for example, turn into questions of ethics, or questions of film, music, and literature become questions of sampling technologies and intellectual property, or questions of war and counterterrorism become questions of computer programming or the design of video games. The study of culture in the twenty-first century must expand the idea of culture if it is to remain relevant and vital not only to the academy but to the world at large.

\section{No Future?}

So, having just articulated a framework for the future of the study of culture in the twenty-first century, why do I want to argue that there is "no future" for the study of culture? Haven't I just articulated a vision of what the future of the study of culture should look like? Well, yes and no. For if I am right about how we should pursue the study of culture in the twenty-first century, then culture as it has been understood for over three hundred years will no longer exist as an autonomous or self-sufficient realm. The future of the study of culture will in that sense be incoherent, and will be usurped by the study of media technologies, or the Anthropocene, or surveillance technologies, and so forth. 
In singling out 'climate' and 'terrorism' I mean to signal not just the importance of interdisciplinarity but the increasingly vital threats that both ecological and geopolitical concerns pose to the continued future not just of the study of culture, but of culture itself. Indeed the idea that there is no future for human culture is today most often associated with questions of climate change, particularly with the concept of the sixth mass extinction or the Anthropocene, which imagines a time after humans are gone and when the impact of humans and their culture on the planet is evident only in nonhuman traces and effects. But arguments about the end of civilization have also been made in response to the proliferation of radical acts of terrorism in the post-9/11 world, and the preemptive responses by nation-states and transnational organizations to the threats posed by such acts. In my five-year tenure as director of C21, we pursued many of these ideas in trying to define and develop the field of twenty-first-century studies. Increasingly our treatment of the future of twenty-first-century studies moved from global to local issues, as we began to address the threats to the future of higher education in Wisconsin from our own state government. Ironically, doing so often entailed in part not the move away from the study of humanities and culture in the name of interdisciplinarity, but the attempt to protect the value of the study of culture for its own sake, without resorting to neoliberal arguments about utility and economic value. Doing so did not mean a refutation of the arguments for interdisciplinarity but a refusal to subordinate those arguments, as they often are in work that goes under the name of digital humanities, to instrumentalist claims for the value of the study of culture. In light of real threats to the reproductive futurism not only of the academic study of culture, but to culture and society as they have come to exist in institutional modernity, we need to do more than make the study of culture interdisciplinary.

Perhaps this is what Ulrich Beck had in mind when he claimed in World at Risk that "cultural criticism" was inadequate as a means of approaching the problems of climate, terrorism, and other twenty-first century threats: "Even the most radical cultural critiques look like caricatures compared to the catastrophic potentials of full-blown modernity. Indeed, one must even go an essential step further; in comparison to the horizon opened up by the negation of the basic principles of modernity, most cultural criticism looks outdated and 'idyllic,' i.e., blind to its own presuppositions or even downright affirmative" (Beck 2009, 229). In dismissing cultural criticism as a means to address the imminent catastrophes of global risk society, Beck takes it to task for failing to realize that the end of nationalist modernity, which the principles of modernity itself have brought about, is not the end of the world but the end of a particular historical formation. He accuses thinkers like Foucault, Adorno, or Weber for 
failing to "realize that where [cultural criticism] sees a world coming to an end the world order is in fact being transformed, that the rules and structures of power and domination are being renegotiated in the global age" (Beck 2009, 219). This renegotiation is prompted by the global risk brought about by such imminent threats as climate change and terrorism: "For there is no greater threat to the Western way and quality of life than the combination of climate change, environmental destruction, dwindling energy and water resources and the wars they could spark" (Beck2009, 65). Beck sees cultural criticism as unable to get past its immanent critique of culture, "which presupposes and reinforces the basic principles of modernity as a measure of value without questioning them" (Beck2009, 229).

While I share Beck's concern with the need to anticipate or premediate future risks, and his analysis of the way in which media proliferate potential global catastrophes, I am not entirely convinced that his invocation of the "“cosmopolitan moment' of world risk society" is necessarily the best alternative to the problems of climate or terrorism that threaten our future. Take, for example, the cosmopolitan anticipation of the always-imminent threat of global terrorism, Islamic or otherwise, which has generated the development of the largest transnational infrastructure of surveillance and securitization in world history. Such transnational cooperation has led to the widespread collection of as much communication and transaction data as technically possible, spearheaded by the NSA and Great Britain's GCHQ, but also supported by the BND in Germany and the DGSI in France, with the aim of preempting potential threats or catastrophes before they happen. But because such preemption is often unsuccessful, we have also witnessed the concomitant development of militarized securitization forces ready to respond immediately to a presumed terrorist attack. My concern here is that the everyday terror of such surveillance and securitization runs the risk of having a far greater negative impact on freedom and safety than the threats they are designed to counteract or preempt. Rather than dismiss cultural criticism for failing to keep up with these new global social formations, there is a role for the study of culture in resisting the abuses and overreaching of security and surveillance.

To put it differently, I would agree with Beck that there is no future for the study of culture if such study does not take as one of its foremost tasks the resistance to the forces of neoliberalism and austerity that threaten the very existence of the academy as we have come to know it. But this resistance cannot simply be a defense of reproductive futurism, of the institutional reproduction of the academic study of culture as it has existed for the past century and more. There is still, I would argue, pace Beck, Latour, and others, a role for critique in the study of culture, but that role must include taking on not only the discourse of 
humans but also the mediations of nonhumans, technical and otherwise (Latour 2004). While we are well on our way to doing just that, to breaking down the traditional barriers between humanistic and non-humanistic disciplines within the walls of the academy, we must at the same time defend the walls of the academy against the barbarians at the gate, the incursions of globalization and securitization brought about to protect us from the threats posed by climate and terrorism. While these threats are very real, and I would not in any way want to diminish them, I want also to challenge the way that these threats have been used as an occasion to strengthen and reinforce the control of global capitalism and militarized securitization over individuals and societies as well as academic institutions. More than twenty years of climate change summits have done little or nothing to reform or dismantle the economic structures of industrial and postindustrial global capitalism that have brought us the environmental and geopolitical catastrophes that we are now facing.

Indeed, we can see in the emergent paradigm of 'resilience' the acceptance of catastrophic change and the determination to create contingency plans to increase the chances that our economic and political institutions will survive in the face of environmental disaster. Barack Obama's historic "Climate Action Plan” of June 2013 was celebrated for being the first official acknowledgment by the US government that global warming has been scientifically proven to be real (Executive Office of the President 2013). But what I found most telling about this plan was not its commitment to cut carbon pollution in America but its recognition that no matter what changes might be able to be made, America (and by extension the world) must act now to prepare itself for the impacts of dramatic climate change by increasing the resilience of infrastructure, buildings, and communities, as well as economic and natural resources. Nowhere does the question of reducing production or commodification or development ever come into the equation, but only the question of developing new technologies that might reduce environmental damage in order to allow capitalism to continue unchecked. In other words, the significance of Obama's “Climate Action Plan” was less its commitment to reverse or even to end global warming than its commitment to prepare the United States to deal with catastrophic environmental change by increasing its 'resilience.'

Similarly, the paradigm of resilience is also at the heart of counter-terrorism planning. Despite the declared goal of using total data surveillance to preempt terrorist attacks a la the pre-crime unit in Steven Spielberg's Minority Report, the collection and mining of data and the unprecedented proliferation of hyper-militarized homeland security police forces is designed mainly to insure that communities and institutions will be resilient in the wake of inevitable acts of terrorism. For like Obama's 'Climate Action Plan,' his and other nations' 
plans to defeat terrorism begin with the acknowledgment that terrorism, like climate change, is inevitable, and therefore focus mainly on preparations for surviving these inevitable attacks. In the case of terrorism what this means is an increase in the militarization and securitization of society, evident in the US in the dramatically increased use of military equipment and tactics by local police forces, spurred on by the National Defense Authorization Act of 1997, which was signed into law during the Clinton administration. While the Obama administration moved to limit such military-style weapons, particularly in the aftermath of the riots in Ferguson, Missouri, in 2014, there has been little change in the degree of militarized police control in the United States, ready to be brought to bear at a moment's notice, as we saw in responses to shootings in places like the gay nightclub in Orlando or, to bring this issue closer to home, on college campuses.

I want to close by briefly addressing the overwhelming show of militarized police force that occurred in response to a murder-suicide at UCLA, on the first of June, 2016, as a way of underscoring my concern that securitization is as much or more to be feared than the acts of criminal violence that are lumped under the rubric of 'terrorism.' For those not familiar with this event, at around 10:00 AM police received the first of several 911 emergency calls reporting three shots fired and possible victims.

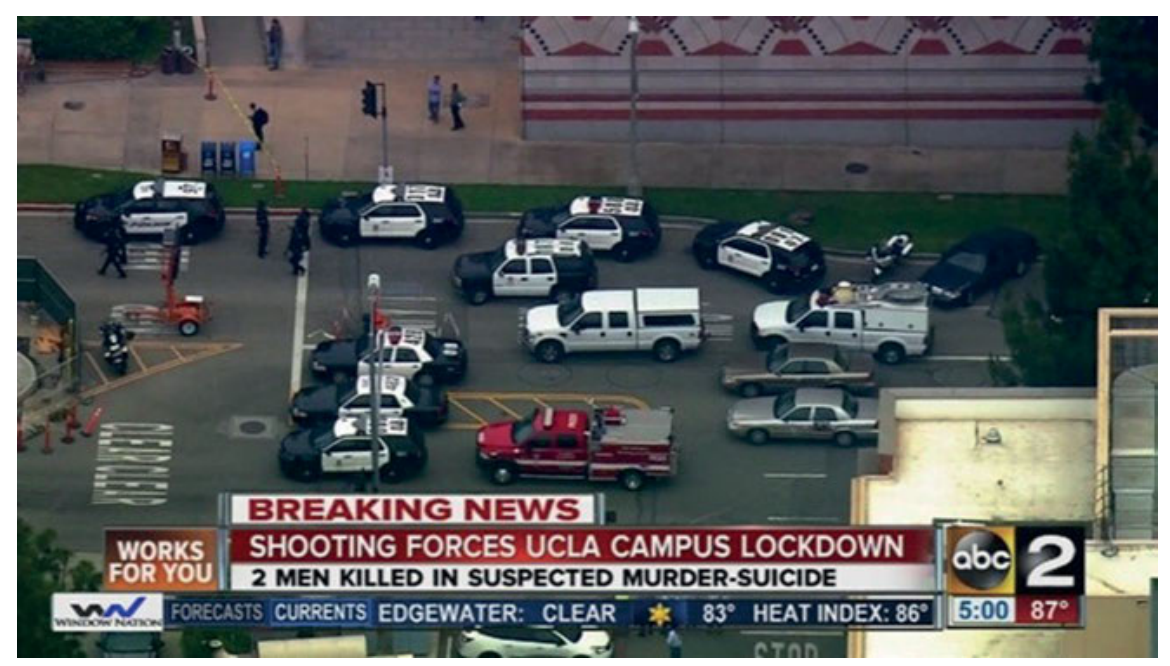

Fig. 1: Police force assembled on UCLA campus [public domain].

According to the Los Angeles Times, the shooting "prompted a massive response from state and federal law enforcement. 


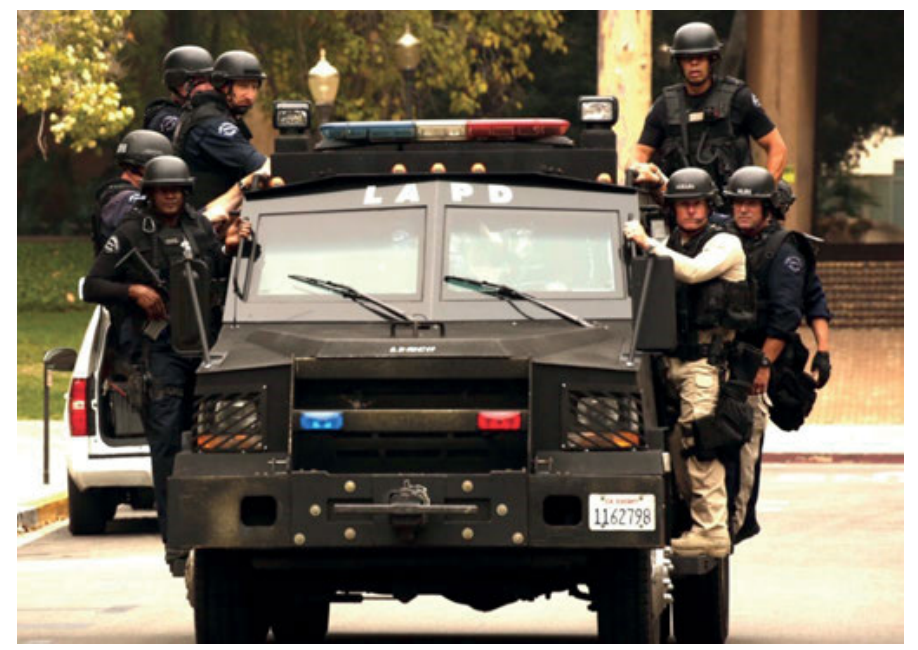

Fig. 2: Militarized police vehicle on UCLA campus [public domain].

Police officers in riot gear ran across campus, guns and battering rams drawn, while students exited buildings with their hands above their heads."

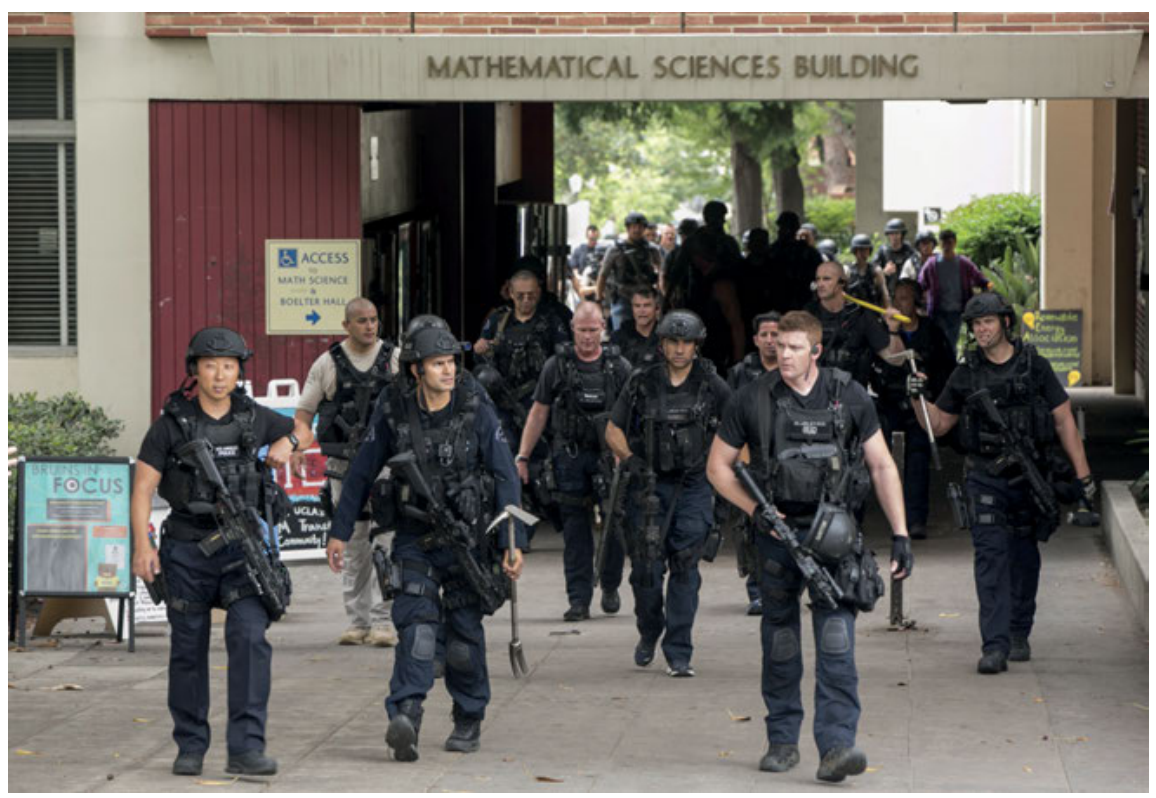

Fig. 3: Police officers in riot gear on UCLA campus [public domain]. 


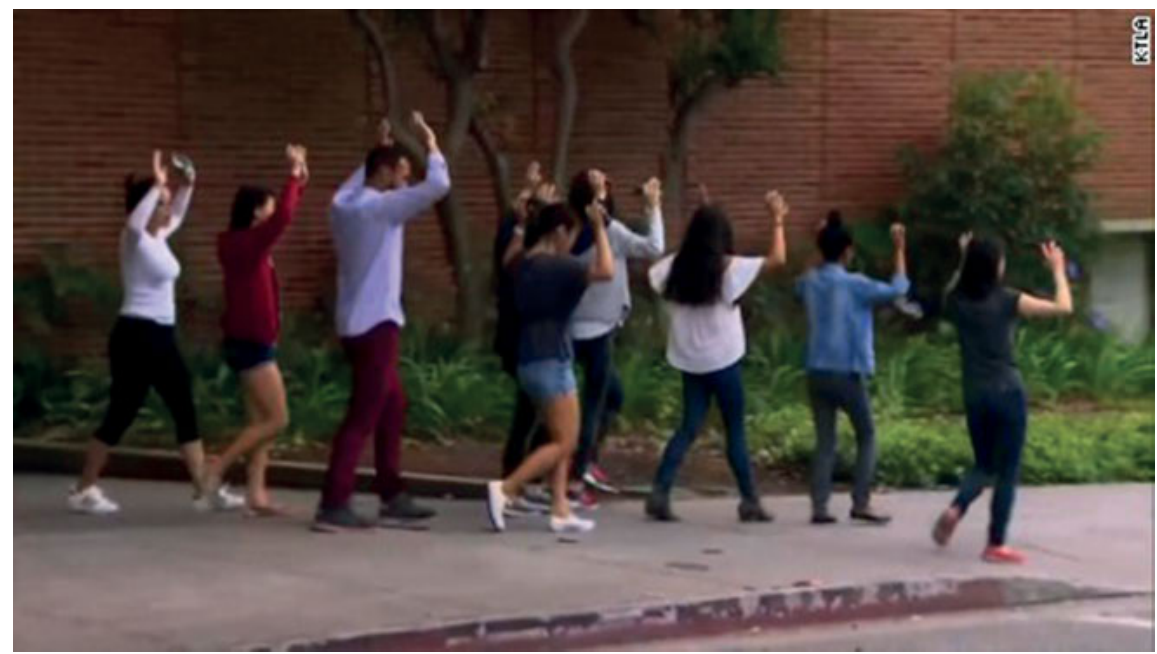

Fig. 4: Students with hands up on UCLA campus [public domain].

In addition to shutting down the campus for two hours, police searched every student carrying a backpack, which as we all know means almost every student on campus.

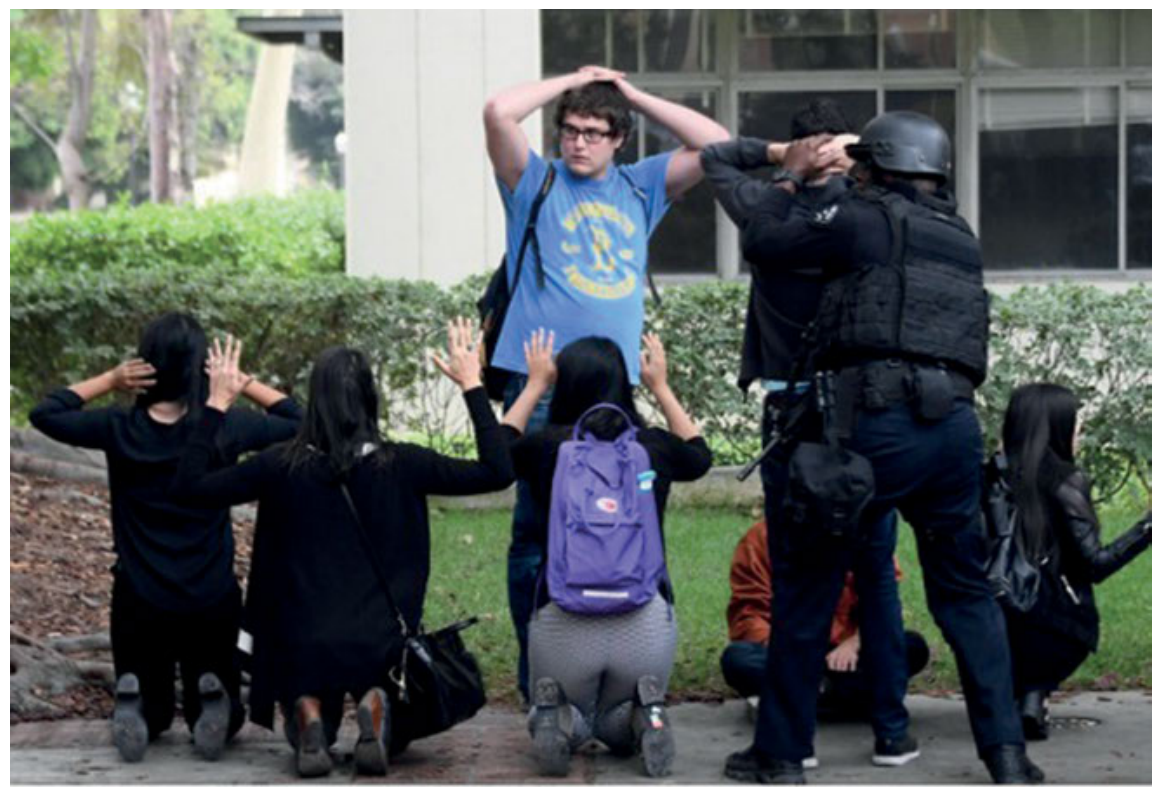

Fig. 5: Students being searched by police on UCLA campus [public domain]. 
In retrospect this response proved to be massively disproportionate to the threat, which ended when the murderer, a former graduate student, killed himself after killing his advisor. Of course, one might argue that because there was no way to know this at the time, it was better for the police to be safe than to be sorry. And this argument makes a certain kind of practical sense. But what I find most troubling about this event is not the murder itself, as tragic as it was, nor the threat of future murders with greater numbers of victims. No, what is most troubling to me is the fact that such a massively militarized law enforcement infrastructure pre-exists and that the authority of the police to take complete control over any public space, including a college campus, is undisputed, particularly when, as was the case in this incident, every student on campus is transformed into a potential suspect.

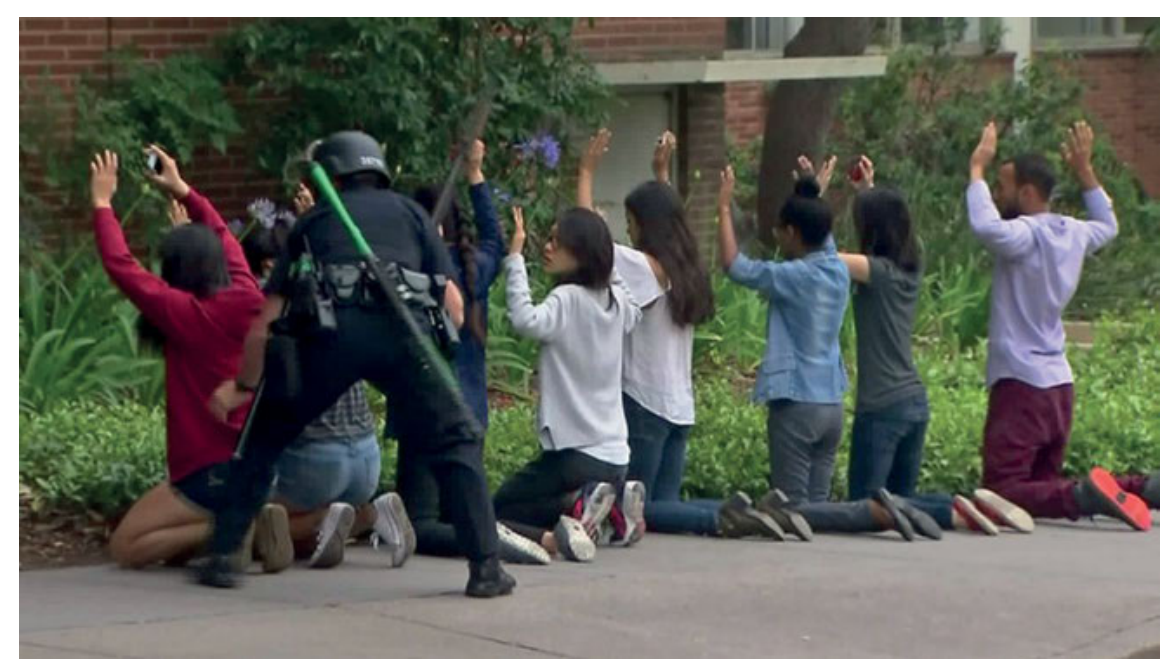

Fig. 6: Students with hands up on their knees being searched by police on UCLA campus [public domain].

The metaphorical force of this event was quite powerful. Even in a supposedly "free" society like the United States, we live, work, and study on campus at the behest of the forces of securitization, and our permission to do so can be revoked at a moment's notice, and with very little evidence or explanation. In light of the mass school shootings that occur periodically in the US, calls to arm schoolteachers or to install armed guards in public schools from kindergarten through high school have only intensified. Indeed, since the Columbine school shootings in 1999 there are more than 10,000 additional police officers stationed in US public 
schools. Clearly these officers have not stopped the shootings - as evidenced, for example, in the February 2018 school shootings in Florida, which killed 17 students and teachers. But what they have done is to criminalize students, who are arrested at a pace of 70,000 per year for offenses that in the past would likely have resulted in disciplinary actions like detention, suspension, or expulsion. And like all police arrests in the US, these arrests have occurred disproportionately to black students ("Militarizing Schools, Criminalizing Students" 2018). Rather than safe spaces for the free exchange of ideas and the education of American youth, schools, colleges, and universities in the United States have become militarized zones to discipline and punish students. To return to the language of the 2016 GCSC/GGK symposium, and to the thesis of this paper, there appears to be no future for the study of culture that is free from the authority of militarized securitization and global capitalism, which means that unless we are vigilant in exposing and resisting these forces there may be no futures for the study of culture at all.

\section{References}

Beck, Ulrich. World at Risk. Cambridge: Polity, 2009.

Benjamin, Walter. "Announcement of the Journal Angelus Novus." W.B. Selected Writings 1. Eds. Howard Eiland and Michael W. Jennings. Cambridge, MA/London: Harvard University Press, 1996.

Edelman, Lee. No Future: Queer Theory and the Death Drive. Durham, NC: Duke University Press, 2004.

Executive Office of the President. The President's Climate Action Plan. 2013.

Latour, Bruno. "Why Has Critique Run out of Steam? From Matters of Fact to Matters of Concern.” Critical Inquiry 30.2 (2004): 225-248.

“Militarizing Schools, Criminalizing Students.” The Real News Network (26 February 2018). <https://therealnews.com/stories/militarizing-schools-criminalizing-students> [accessed: 10 October 2019].

Sex Pistols. “God Save the Queen.” Never Mind the Bollocks, Here's the Sex Pistols. London: Virgin Records, 1977. 